\title{
Emergent stenting after intravenous thrombolysis for isolated basilar artery dissection in a patient with acute ischemic stroke: a case report
}

\author{
Toshiaki Goda ${ }^{1 *} \mathbb{D}$, Naoki Oyama', Takanori Iwamoto ${ }^{1}$, Hiroki Takai ${ }^{2}$ Shunji Matsubara², Masaaki Uno²
} and Yoshiki Yagita'

\begin{abstract}
Background: Isolated basilar artery dissection (IBAD) is a rare but important cause of ischemic stroke. Anti-thrombotic therapy is often used to treat IBAD-related ischemic stroke, but selected cases might need more aggressive treatment. There is no previous report of emergent stenting for IBAD-related ischemic stroke after intravenous thrombolysis.
\end{abstract}

Case presentation: A 53-year-old Japanese woman was admitted to our hospital with disturbance of consciousness, right hemiplegia, severe dysarthria, and total gaze paralysis. Brain magnetic resonance imaging revealed no ischemic lesion, but magnetic resonance angiography showed stenosis in the basilar artery. After initiation of intravenous thrombolysis, her neurological symptoms dramatically improved. Five hours later, however, her symptoms deteriorated again. Cerebral angiography showed IBAD. Emergent stenting was successfully performed. At 90 days after stroke onset, she had no significant disability, with a modified Rankin scale score of 1.

Conclusions: Emergent stenting can be an effective treatment for patients with IBAD-related ischemic stroke who are resistant to IV-rtPA.

Keywords: Basilar artery dissection, Ischemic stroke, Intravenous thrombolysis, Emergent stenting

\section{Background}

Isolated basilar artery (BA) dissection (IBAD) is a rare but important cause of ischemic stroke (incidence, $1 / 400,000$ /year) [1]. It is known to have a poor prognosis, with a mortality rate ranging from 10 to $78.9 \%$ [2]. Anti-thrombotic therapy is often used to treat IBADrelated ischemic stroke, but selected cases might need more aggressive treatment [3]. Although some cases of endovascular stenting for IBAD have been reported, the

*Correspondence: to4aki.5da.takaraduka@gmail.com

1 Department of Stroke Medicine, Kawasaki Medical School, Matsushima, Kurashiki, Okayama 577701-0192, Japan

Full list of author information is available at the end of the article procedures were performed electively for progressive ischemic symptoms despite adequate anti-thrombotic therapy [2-5]. To the best of our knowledge, there is no previous report of emergent stenting for IBAD-related ischemic stroke after intravenous thrombolysis. We report a case of IBAD in a patient with acute ischemic stroke who underwent emergent stenting for neurological deterioration after intravenous thrombolysis.

\section{Case presentation}

A 53-year-old Japanese woman with a medical history of diabetes mellitus and no other risk factors for arteriosclerosis was admitted to our hospital. Physical examination showed a Glasgow Coma Scale score of original author(s) and the source, provide a link to the Creative Commons licence, and indicate if changes were made. The images or other third party material in this article are included in the article's Creative Commons licence, unless indicated otherwise in a credit line to the material. If material is not included in the article's Creative Commons licence and your intended use is not permitted by statutory regulation or exceeds the permitted use, you will need to obtain permission directly from the copyright holder. To view a copy of this licence, visit http://creativecommons.org/licenses/by/4.0/. The Creative Commons Public Domain Dedication waiver (http://creativeco mmons.org/publicdomain/zero/1.0/) applies to the data made available in this article, unless otherwise stated in a credit line to the data. 
E3V3M4, right hemiplegia, severe dysarthria, and total gaze paralysis. The National Institute of Health Stroke Scale (NIHSS) score was 22. Brain magnetic resonance imaging (MRI) at 90 minutes from the onset of symptoms revealed no high-intensity area on diffusionweighted imaging (Fig. 1a). Brain magnetic resonance angiography showed stenosis in the BA (Fig. 1b). After initiation of intravenous administration of recombinant tissue plasminogen activator (IV-rtPA), neurological symptoms improved with an NIHSS of 4; however, 5 hours after IV-rtPA, the symptoms deteriorated again with an NIHSS of 22. Cerebral angiography showed
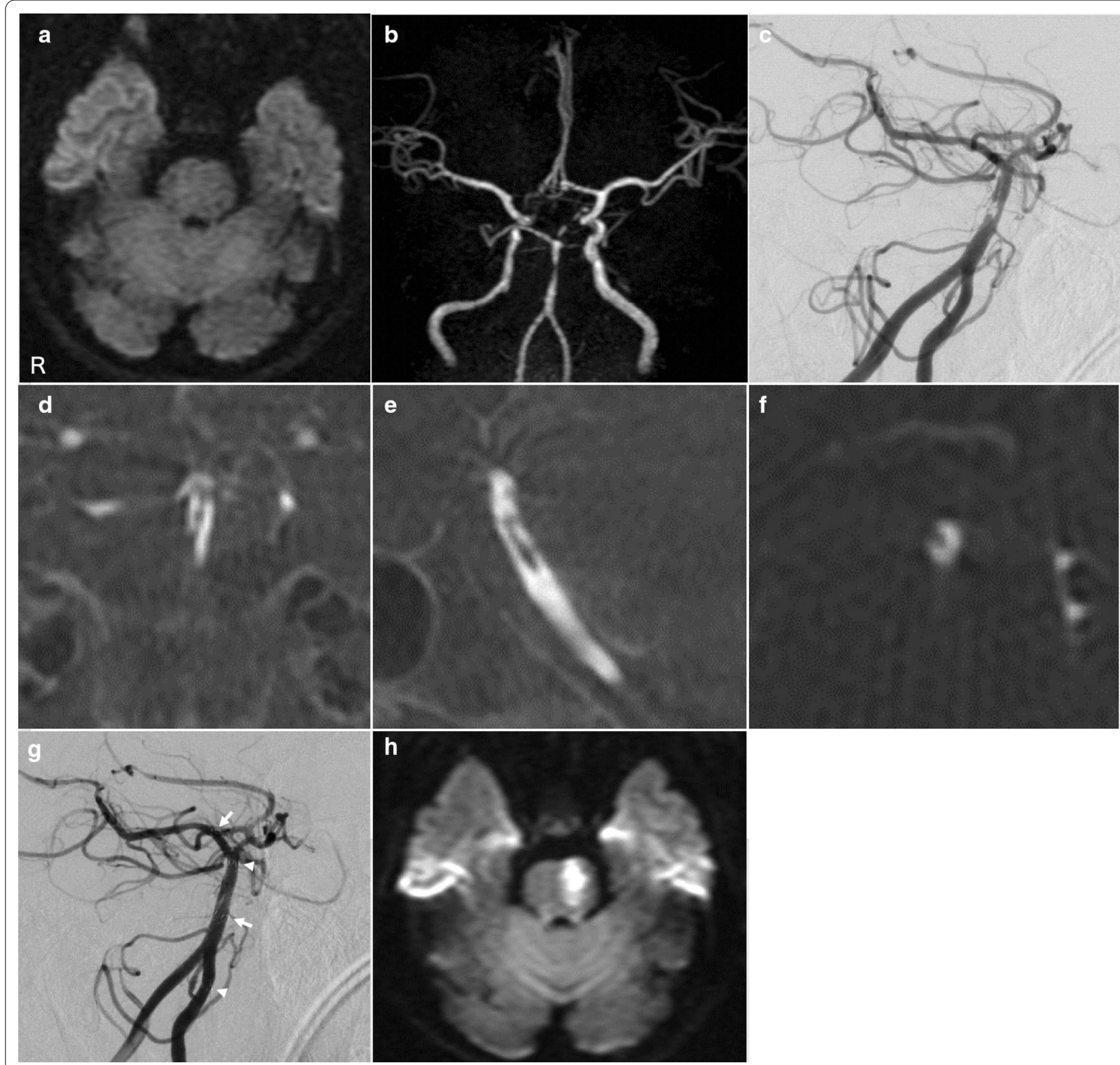

Fig. 1 a Brain magnetic resonance imaging (MRI) at 90 minutes from symptom onset showing no high-intensity area on diffusion-weighted imaging (DWI). b Brain magnetic resonance angiography showing stenosis in the middle portion of the basilar artery (BA). c Cerebral angiography $\left(45^{\circ}\right.$ right-anterior oblique view) showing intimal flap and double lumen in the middle and distal portions of the BA. Maximum intensity projection images of 3D rotational angiography showing double lumen of the BA in the coronal view (d), sagittal view (e), and axial view (f). $\mathbf{g}$ Cerebral angiography ( $45^{\circ}$ right-anterior oblique view) after stenting. Enterprise VRD $4.5 \times 22 \mathrm{~mm}^{2}$ (arrow: distal and proximal marker) and $4.5 \times 28 \mathrm{~mm}^{2}$ (arrowhead: distal and proximal marker) was deployed from the P1 portion of the right posterior cerebral artery to the V4 portion of the left vertebral artery. $\mathbf{h}$ Brain MRI on day 6 showing left-sided pontine infarction on DWI 
severe stenosis and double lumen in the BA (Fig. 1cf). We deployed Enterprise Vascular Reconstruction Device (VRD) $4.5 \times 22 \mathrm{~mm}^{2}$ and $4.5 \times 28 \mathrm{~mm}^{2}$ (Johnson \& Johnson Codman, Miami, FL, USA) from the right posterior cerebral artery to the left vertebral artery (Fig. 1g) after administration of $200 \mathrm{mg}$ of aspirin and $300 \mathrm{mg}$ of clopidogrel. On day 2, $100 \mathrm{mg} /$ day aspirin and $75 \mathrm{mg} /$ day clopidogrel were initiated. Although MRI revealed small pontine infarction (Fig. 1h), the patient's neurological deficit gradually improved. She was transferred to the rehabilitation center on day 23 with an NIHSS of 3. At 90 days from stroke onset, she had no significant disability with an NIHSS of 0 and a modified Rankin scale score of 1.

\section{Discussion and conclusions}

This is the first case report of a patient with acute ischemic stroke due to IBAD who underwent emergent stenting for neurological deterioration after IV-rtPA. Although some cases of stenting for IBAD have been reported, most of the procedures in these cases were performed after at least 3 days of dual antiplatelet therapy [2-5], and there is only one report of stenting in the hyper-acute phase of ischemic stroke [3]. There is no previous report of emergent stenting after IV-rtPA for IBAD-related ischemic stroke. Our case suggests that even for patients with IBAD-related ischemic stroke who are resistant to IV-rtPA, stenting can be a safe and effective treatment option.

Optimal treatment for ischemic stroke with IBAD has not been established. In clinical practice, anticoagulant or antiplatelet therapies are usually used. However, conservative management occasionally results in a poor prognosis $[3,6]$. Efficacy and safety of IV-rtPA for ischemic stroke due to intracranial artery dissection have not been established, and in some cases, neurological deterioration after IV-rtPA is noted [7]. For patients presenting with progressive ischemia despite adequate medical treatments including IV-rtPA, stenting can be an alternative treatment option with a relatively good prognosis.

The benefits of stenting for IBAD are not completely understood. Occlusion of perforating branches of the BA is reported to be the main mechanism underlying IBADrelated ischemic stroke [8]. We speculate that thrombus formation in the false lumen might obstruct the blood flow in perforating branches by compressing the origin of these branches, resulting in brainstem infarction. IVrtPA can prevent thrombus formation, but its efficacy is transient. In contrast, stenting can repair the intimal flap, which is the inflow route of the false lumen. Reduced blood flow into the false lumen will lead to less thrombus formation in this structure.

In conclusion, emergent stenting can be an effective treatment for patients with IBAD-related ischemic stroke who are resistant to IV-rtPA.

\section{Abbreviations}

BA: Basilar artery; IBAD: Isolated basilar artery dissection; NIHSS: National Institute of Health Stroke Scale; MRI: Magnetic resonance imaging; IV-rtPA: Intravenous recombinant tissue plasminogen activator; DWI: Diffusionweighted imaging.

\section{Acknowledgements}

None.

Authors' contributions

TG was responsible for the conception and design of the work as well as data analysis and interpretation. NO, TI, HT, SM, MU, and YY were responsible for data collection. TG drafted the article, which was critically revised by $\mathrm{NO}, \mathrm{TI}, \mathrm{HT}, \mathrm{SM}, \mathrm{MU}$, and $\mathrm{YY}$. TG, NO, TI, HT, SM, MU, and YY were responsible for the final approval of the version to be published.

\section{Funding}

The authors have no funding to declare.

\section{Availability of data and materials}

Not applicable.

Ethics approval and consent to participate Not applicable.

\section{Consent for publication}

Written informed consent was obtained from the patient for publication of this case report and any accompanying images. A copy of the written consent is available for review by the Editor-in-Chief of this journal.

\section{Competing interests}

The authors declare that they have no competing interests.

\section{Author details}

${ }^{1}$ Department of Stroke Medicine, Kawasaki Medical School, Matsushima, Kurashiki, Okayama 577701-0192, Japan. ${ }^{2}$ Department of Neurosurgery, Kawasaki Medical School, Okayama, Japan.

Received: 8 August 2019 Accepted: 11 January 2021

Published online: 09 March 2021

References

1. Ruecker M, Furtner M, Knoflach M, Werner P, Gotwald T, Chemelli A, et al. Basilar artery dissection: Series of 12 consecutive cases and review of the literature. Cerebrovas Dis. 2010;30:267-76.

2. Li L, Li T, Xue J, Wang Z, Bai W, Zhu L, et al. Stent treatment for basilar artery dissection: A single-center experience of 21 patients. Interv Neuroradiol. 2016:22:260-5.

3. Kim BM, Suh SH, Park SI, Shin YS, Chung EC, Lee MH, et al. Management of clinical outcome of acute basilar artery dissection. Am J Neuroradiol. 2008:29:1937-41.

4. Jiang C, Li Q, Liu JM, Huang QH. Endovascular treatment for the basilar artery dissection. Cardiovasc Intervent Radiol. 2014;37:646-56.

5. Li C, Li Y, Jiang C, Wu Z, Wang Y, Yang X. Stent alone treatment for dissections and dissecting aneurysms involving the basilar artery. J Neurointerv Surg. 2015;7:50-5.

6. Pozzati E, Andreoli A, Padovani R, Nuzzo G. Dissecting aneurysms of the basilar artery. Neurosurgery. 1995;36:254-8.

7. Bernardo F, Nannoni S, Strambo D, Bartolini B, Michel P, Sirimarco G. Intravenous thrombolysis in acute ischemic stroke due to intracranial 
artery dissection: a single-center case series and a review of literature. J Thromb Thrombolysis. 2019;13:1-6.

8. Kwon JY, Kim N-Y, Suh DC, Kang DW, Kwon SU, Kim JS. Intracranial and extracranial arterial dissection presenting with ischemic stroke: lesion location and stroke mechanism. J Neurol Sci. 2015;358:371-6.

\section{Publisher's Note}

Springer Nature remains neutral with regard to jurisdictional claims in published maps and institutional affiliations.
Ready to submit your research? Choose BMC and benefit from:

- fast, convenient online submission

- thorough peer review by experienced researchers in your field

- rapid publication on acceptance

- support for research data, including large and complex data types

- gold Open Access which fosters wider collaboration and increased citations

- maximum visibility for your research: over 100M website views per year

At BMC, research is always in progress.

Learn more biomedcentral.com/submissions 